American Journal of Economics and Business Administration 2 (3): 317-322, 2010

ISSN 1945-5488

(C) 2010 Science Publications

\title{
A Stock Dependent Economic Order Quantity Model for Perishable Items Under Inflationary Conditions
}

\author{
Singh Sarbjit and Singh Shiv Raj \\ Department of Mathematics, Institute of Management Technology, \\ 603, Khullar Appts, Byramji Town, Nagpur 440013, \\ Devnagari, Degree College, Meerut
}

\begin{abstract}
Problem statement: In most of the earlier inventory models, effect of inflation has been ignored, which is playing pilot role in present environment. In this article, we have proposed an economic order quantity model for deteriorating items having stock dependent demand (whose demand varies with the stock) under the effect of inflation. Approach: Firstly, problem is framed in the form of linear differential equation model and then this model has been solved with general solution technique of linear differential equations. Using the solution the expression for total cost of inventory has been obtained. Results: Using total cost equation an optimal order quantity is obtained and convexity of various costs is also studied. This model helps retailer to decide his economic order quantity for deteriorating items having stock dependent demand. The consideration of effect of inflation makes this model more relevant for present business environment. Conclusion: The convexity of various costs proves the validity of this model. The effect of inflation with two different rates is also studied in tables below considering both constant as well as stock dependent demand. The graph of these tables shows that the optimal inventory cost increases with increase in number of cycles it increases rapidly in starting but becomes stable for large number of cycles. The proposed model can be extended in several ways. For instance, we may generalize the model to allow for shortages, quantity discounts, time value of money, finite replenishment rate, permissible delay in payments and others.
\end{abstract}

Key words: Stock dependent demand, inflationary conditions, variable deterioration, convexity

\section{INTRODUCTION}

The observation of supermarkets reveals that the demand rate is usually influenced by the amount of stock level, that is, the demand rate may go up or down with the increase or decrease in on-hand stock level. For example large number of items in a departmental store will make buy more items and low stocks of fruits and vegetables might raise the perception that they are not fresh. As pointed by Levin et al. (1972), "at times the presence of inventory has a motivational effect on the people around it. It is common belief that large piles of goods displayed in a supermarket will lead the customer to buy more". Silver and Peterson (1985) observed that a sale at the retail level is directly proportional to the amount of inventory displayed. This fact attracted a number of researchers to drive EOQ models focused on stock-dependent rate patterns. Gupta and Vrat (1986) were the first to introduce stock dependent demand as the function of initial inventory level followed by Baker and Urban (1988) who formulated a model in which sales were directly affected by the allocation of shelf space, they established an Economic Order Quantity model (or EOQ) for a power-form inventory-level-dependent demand pattern (i.e., the demand rate at time $t$ is $D(t)$ $=\alpha[\mathrm{I}(\mathrm{t})]^{\beta}$, where $\mathrm{I}(\mathrm{t})$ is the inventory level, $\alpha>0$ and $0<\beta<1$ ). Mandal and Phaujdar (1989) who used various stock dependent demand rate for non-perishable items have considered linear stock dependent demand (i.e., $\mathrm{D}(\mathrm{t})=\alpha+\beta \mathrm{I}(\mathrm{t})$, where $\alpha$ and $\beta>0$ ). Datta and Pal (1990) extended Mandal and Phaujdar (1989) work for deteriorating items with assumption that demand rate is a linear function of the on-hand inventory by allowing shortages, which are completely backlogged for both finite and infinite time horizons. Some other works related to this area are Goh (1994) concentrated on the situation that defined demand rate as a polynomial function, dependent on instantaneous stock level

Corresponding Author: Singh Sarbjit, Department of Mathematics, Institute of Management Technology, 603, Khullar Appts, Byramji Town, Nagpur 440013, Devnagari, Degree College, Meerut 
followed by Padmanabhan and Vrat (1995) and Ray and Chaudhari (1997) also considered an EOQ model with stock dependent demand, shortage, inflation and time discounting and Giri and Chaudhari (1998) who extended the EOQ to allow for non a non linear holding cost. Mandal and Maiti (1999) also developed an inventory model of damageable items with variable replenishment rate, stock-dependent demand and some units in hand. Subbaiah et al. (2004) developed inventory models for perishable items having stock dependent demand followed by Teng and Chang (2005) who established an economic production quantity models for deteriorating items with price-and stock-dependent demand (i.e., $\mathrm{D}(\mathrm{t}, \mathrm{p})=\alpha(\mathrm{p})+\beta 1(\mathrm{t})$, where $\beta$ is a non-negative constant, $\alpha(p)$ is a non negative function of $\mathrm{p}$ with $\alpha^{\prime}(\mathrm{p})=\mathrm{d}(\alpha) / \mathrm{dp}<0$.). Hou (2006) considered a model for deteriorating items having stock dependent demand with constant rate of deterioration under the effect of inflation and time value of money.

In classical inventory models the effect of inflation is disregarded, but with globalization and changing political situations the effects of inflation cannot be ignored. The pioneer in this direction was Buzacott (1975), who developed the first EOQ model taking inflation into account. In the same year, Mishra (1975) also developed an economic order quantity model incorporating inflationary effects. Mishra (1979) also developed a discount model in which the effect of both inflation and time value of money was considered. Chandra and Bahner (1985) had developed models to investigate the effects of inflation and time value of money on optimal ordering policies. Su et al. (1996) developed model under inflation for stock dependent consumption rate and exponential decay.

In recent years the study of deteriorating items has gained great importance. Ghare and Schrader (1973) were the first to use the concept of deterioration followed by Covert and Philip (1973) who formulated a model with variable rate of deterioration rate with two parameter Weibull distribution, which was further extended by Shah (1977). Sarkar et al. (2000) established a supply chain model for perishable products under inflation and time value of money

In this study we have extended the work of Hou (2006) and Frimpong and Oteng-Abayie, (2010) by considering variable rate of deterioration, this model is best suited for items like fruits, vegetables and milk products whose deterioration rate increases with time. In this study we have tried to consider a present market situation with more relevant rate of inflation for items having stock dependent demand.

\section{MATERIALS ANDMETHODS}

Moreover, special cases of the model are shown by choosing appropriate values of the various parameters of the model in the Table 1-4 which illustrate the proposed model's effectiveness.

\section{Assumptions and notations:}

$\mathrm{T}=$ Length of inventory cycle

$\theta \mathrm{t}=$ Variable rate of deterioration

$\mathrm{K}=$ constant rate of inflation

$\mathrm{I}(\mathrm{t})=$ Inventory level at time $\mathrm{t}$

$\mathrm{Q}=$ Ordering quantity

$C(t)=$ Unit purchase price of item at time $t$ i.e.:

$$
\mathrm{C}(\mathrm{t})=\mathrm{C}_{0}\left[\frac{\mathrm{K}^{\mathrm{r}} \mathrm{t}^{\mathrm{r}-1}}{(\mathrm{r}-1) !}\right]
$$

where, $\mathrm{C}_{0} \mathrm{~K}$ is the unit price at $\mathrm{r}=1$, where $\mathrm{r}$ is positive integer $\geq 1 \mathrm{~A}(\mathrm{t})$ Ordering cost denotes an order placed at time t, i.e.:

$$
\mathrm{A}(\mathrm{t})=\mathrm{A}_{0}\left[\frac{\mathrm{K}^{\mathrm{r}} \mathrm{t}^{\mathrm{r}-1}}{(\mathrm{r}-1) !}\right]
$$

Where:

$\mathrm{A}_{0} \mathrm{~K}=$ The ordering cost $\mathrm{r}=1$

$\mathrm{H}$ = Length of the whole planning horizon

$\mathrm{m}=$ Number of cycles in a year

$\mathrm{C}_{\mathrm{A}}=$ Total ordering cost in $(0, \mathrm{H})$

$\mathrm{C}_{\mathrm{P}} \quad=$ Total purchasing cost in $(0, \mathrm{H})$

$\mathrm{C}_{\mathrm{H}}=$ Total holding costing in $(0, \mathrm{H})$

- The inventory involves only a single item

- Lead time is zero

- There is no use of deteriorated units

- Replenishment rate is infinite i.e., replenishment is instantaneous

Demand is stock dependent i.e., it depends on the stock available, given by $\lambda=\alpha+\beta Q^{r_{1}}$, where $\alpha$ and $\beta$ are constant.

Mathematical model and analysis: For constant replenishment interval, constant replenishment period is:

$\mathrm{T}=\frac{\mathrm{H}}{\mathrm{m}}$

The inventory depletes not only with stock dependent demand but also with variable rate of deterioration:

$$
\frac{\mathrm{dI}(\mathrm{t})}{\mathrm{dt}}+\theta \mathrm{tI}(\mathrm{t})=\lambda
$$


Am. J. of Economics and Business Administration 2 (3): 317-322, 2010

Table 1: Where $\mathrm{r}=1$

\begin{tabular}{|c|c|c|c|c|}
\hline No. of cycles in a year $M$ & Ordering $\operatorname{cost} C_{A}$ & Purchasing cost $C_{P}$ & Holding $\operatorname{cost} C_{H}$ & Total $\operatorname{cost} C_{T}$ \\
\hline 2 & 105 & 8190.00 & 2286.900 & 10581.90 \\
\hline 3 & 210 & 9534.00 & 1874.208 & 11618.20 \\
\hline 4 & 315 & 10300.50 & 1515.780 & 12131.28 \\
\hline 6 & 525 & 10867.50 & 927.670 & 12320.17 \\
\hline \multicolumn{5}{|l|}{ Table 2: Where $\mathrm{r}=2$} \\
\hline No. of cycles in a year M & Ordering $\operatorname{cost} \mathrm{C}_{\mathrm{A}}$ & Purchasing $\operatorname{cost} C_{P}$ & Holding $\operatorname{cost} \mathrm{C}_{\mathrm{H}}$ & Total cost $\mathrm{C}_{\mathrm{T}}$ \\
\hline 2 & 661.5 & 51597.00 & 14407.47 & 66665.97 \\
\hline 3 & 1323.0 & 60064.20 & 11807.51 & 73194.71 \\
\hline 4 & 1984.5 & 62511.75 & 9549.41 & 74045.66 \\
\hline 6 & 3307.5 & 68365.25 & 5821.20 & 77593.95 \\
\hline \multicolumn{5}{|l|}{ Table 3: Where $r=1$} \\
\hline No. of cycles in a year M & Ordering cost $C_{A}$ & Purchasing cost $C_{P}$ & Holding cost $\mathrm{C}_{\mathrm{H}}$ & Total cost $\mathrm{C}_{\mathrm{T}}$ \\
\hline 2 & 105 & 8190.00 & 2930.20 & 11225.20 \\
\hline 3 & 210 & 9534.00 & 2293.45 & 12037.45 \\
\hline 4 & 315 & 10300.50 & 1803.47 & 12418.97 \\
\hline 6 & 525 & 10867.50 & 1067.74 & 12460.24 \\
\hline \multicolumn{5}{|l|}{ Table 4: Where $r=2$} \\
\hline No. of cycles in a year M & Ordering $\operatorname{cost} \mathrm{C}_{\mathrm{A}}$ & Purchasing $\operatorname{cost} C_{P}$ & Holding $\operatorname{cost} \mathrm{C}_{\mathrm{H}}$ & Total cost $\mathrm{C}_{\mathrm{T}}$ \\
\hline 2 & 661.5 & 51597.00 & 18460.29 & 70718.79 \\
\hline 3 & 1323.0 & 6006.20 & 14448.80 & 75836.00 \\
\hline 4 & 1984.5 & 62511.75 & 11361.40 & 7587.65 \\
\hline 6 & 3307.5 & 68465.25 & 6700.20 & 78472.95 \\
\hline
\end{tabular}

where, $0 \leq \mathrm{t} \leq \mathrm{T}$.

This gives inventory at any time by:

$$
I(t)=\lambda\left[\frac{\theta}{6}\left(T^{3}-t^{3}\right)+(T-t)\right] e^{-\theta t^{2} / 2}
$$

Which initial inventory at any time $\mathrm{t}=0$ is given by:

$$
\mathrm{I}_{0}=\mathrm{Q}=\lambda\left[\frac{\theta \mathrm{T}^{3}}{6}+\mathrm{T}\right]
$$

For inventory carrying cost, let $\mathrm{I}$ (t) be the inventory level at time t. since $\mathrm{Q}=\lambda\left[\frac{\theta \mathrm{T}^{3}}{6}+\mathrm{T}\right]$, we have:

$$
\mathrm{I}(\mathrm{nT}+\mathrm{t})=\lambda\left[\frac{\theta}{6}\left(\mathrm{~T}^{3}-\mathrm{t}^{3}\right)+(\mathrm{T}-\mathrm{t})\right] \mathrm{e}^{-\mathrm{\theta}^{2} / 2}
$$

and carrying cost in $(0, \mathrm{H})$ is:

$$
\begin{gathered}
C_{H}=i \sum_{n=0}^{m-1} \mathrm{C}(n T) \int_{0}^{T} \mathrm{I}(\mathrm{nT}+\mathrm{t}) \mathrm{dt} \\
=\mathrm{iC}_{0} \sum_{\mathrm{n}=0}^{\mathrm{m}-1}\left[\mathrm{~K}^{\mathrm{r}} \frac{(\mathrm{nT})^{\mathrm{r}-1}}{(\mathrm{r}-1) !}\right]_{0}^{\mathrm{T}} \lambda\left[\frac{\theta}{6}\left(\mathrm{~T}^{3}-\mathrm{t}^{3}\right)+(\mathrm{T}-\mathrm{t})\right] \mathrm{e}^{-\theta \mathrm{t}^{2} / 2} \mathrm{dt} \\
\mathrm{C}_{\mathrm{H}}=\mathrm{iC}_{0} \lambda\left[\mathrm{K}^{\mathrm{r}} \frac{(\mathrm{nT})^{\mathrm{r}-1} \mathrm{~S}}{(\mathrm{r}-1) !}\right]\left[\begin{array}{l}
\left(\frac{\mathrm{T}^{2}}{2}-\frac{\vartheta \mathrm{T}^{4}}{24}\right) \\
+\frac{\vartheta}{6}\left(\frac{3 \mathrm{~T}^{4}}{4}-\frac{\vartheta \mathrm{T}^{6}}{12}\right)
\end{array}\right]
\end{gathered}
$$

Let $\mathrm{A}(\mathrm{t})$ and $\mathrm{C}(\mathrm{t})$ denote the replenishment cost and unit purchase cost at time $t$, respectively. The replenishment cost in $(0, \mathrm{H})$ is:

$\mathrm{C}_{\mathrm{A}}=\mathrm{A}(0)+\mathrm{A}(\mathrm{T})+\mathrm{A}(2 \mathrm{~T})+\ldots \ldots . . \mathrm{A}((\mathrm{n}-1) \mathrm{T})$

$=\mathrm{A}_{0}\left[\frac{\mathrm{K}^{\mathrm{r}} \mathrm{T}^{\mathrm{r}-1} \mathrm{~S}}{(\mathrm{r}-1) !}\right]$

where, $S=\left[1^{r-1}+2^{r-1}+\ldots \ldots \ldots . .(m-1)^{r-1}\right]$.

and purchasing cost in $(0, \mathrm{H})$ is:

$$
\begin{aligned}
\mathrm{C}_{\mathrm{p}} & =\mathrm{Q}[\mathrm{C}(0)+\mathrm{C}(\mathrm{T})+\mathrm{C}(2 \mathrm{~T})+\ldots \ldots . \mathrm{C}((\mathrm{n}-1) \mathrm{T}) \\
& =\mathrm{QC}_{0}\left[\frac{\mathrm{K}^{\mathrm{r}} \mathrm{T}^{\mathrm{r}-1} \mathrm{~S}}{(\mathrm{r}-1) !}\right]
\end{aligned}
$$

From Eq. $6-8$ the total cost over $(0, \mathrm{H})$ is given by:

$$
\begin{aligned}
\mathrm{C}_{\mathrm{T}}=\mathrm{C}_{\mathrm{A}}+\mathrm{C}_{\mathrm{P}}+\mathrm{C}_{\mathrm{H}}=\mathrm{A}_{0}\left[\frac{\mathrm{K}^{\mathrm{r}} \mathrm{T}^{\mathrm{r}-1} \mathrm{~S}}{(\mathrm{r}-1) !}\right]+\mathrm{QC}_{0}\left[\frac{\mathrm{K}^{\mathrm{r}} \mathrm{T}^{\mathrm{r}-1} \mathrm{~S}}{(\mathrm{r}-1) !}\right] \\
+\mathrm{iC}_{0} \lambda\left[\mathrm{K}^{\mathrm{r}} \frac{(\mathrm{nT})^{\mathrm{r}-1} \mathrm{~S}}{(\mathrm{r}-1) !}\right]\left[\begin{array}{l}
\left(\frac{\mathrm{T}^{2}}{2}-\frac{\vartheta \mathrm{T}^{4}}{24}\right) \\
+\frac{\vartheta}{6}\left(\frac{3 \mathrm{~T}^{4}}{4}-\frac{\vartheta \mathrm{T}^{6}}{12}\right)
\end{array}\right]
\end{aligned}
$$

Neglecting term of $\theta^{2}$ as $\theta$ is very small:

$$
\mathrm{C}_{\mathrm{T}}=\left[\mathrm{A}_{0}+\mathrm{QC}_{0}+\lambda \mathrm{iC}_{0}\left(\frac{\mathrm{T}^{2}}{2}+\frac{\theta \mathrm{T}^{4}}{12}\right)\right]\left[\frac{\mathrm{K}^{\mathrm{r}} \mathrm{T}^{\mathrm{r}-1} \mathrm{~S}}{(\mathrm{r}-1) !}\right]
$$


Where:

$$
\mathrm{Q}=\lambda\left[\frac{\theta \mathrm{T}^{3}}{6}+\mathrm{T}\right]
$$

$$
\begin{aligned}
& \mathrm{Q}=\lambda \mathrm{T}\left[\frac{\theta \mathrm{T}^{2}}{6}+1\right] \\
& \lambda=\frac{6 \mathrm{Q}}{\mathrm{T}\left(6+\theta \mathrm{T}^{2}\right)}
\end{aligned}
$$

$$
\mathrm{C}_{\mathrm{T}}=\left[\mathrm{A}_{0}+\mathrm{QC}_{0}+\frac{6 \mathrm{Q}}{\mathrm{T}\left(6+\theta \mathrm{T}^{2}\right)} \mathrm{iC}_{0}\left(\frac{\mathrm{T}^{2}}{2}+\frac{\theta \mathrm{T}^{4}}{12}\right)\right]\left[\frac{\mathrm{K}^{\mathrm{r}} \mathrm{T}^{\mathrm{r}-1} \mathrm{~S}}{(\mathrm{r}-1) !}\right]
$$

$\mathrm{C}_{\mathrm{T}}=\left[\mathrm{A}_{0}+\mathrm{QC}_{0}+\frac{\mathrm{iC}_{0} \mathrm{QT}}{2}\right]\left[\frac{\mathrm{K}^{\mathrm{r}} \mathrm{T}^{\mathrm{r}-1} \mathrm{~S}}{(\mathrm{r}-1) !}\right]$

In the above model, consumption rate is stock dependent and given by the relation $\lambda=\alpha+\beta Q^{r_{1}}$. Putting this in Eq. 11 gives:

$\mathrm{C}_{\mathrm{T}}=\left[\mathrm{A}_{0}+\mathrm{QC}_{0}+\frac{\mathrm{iC}_{0} \mathrm{QN}(\mathrm{Q})}{2}\right]\left[\frac{\mathrm{K}^{\mathrm{r}}[\mathrm{N}(\mathrm{Q})]^{\mathrm{r}-1} \mathrm{~S}}{(\mathrm{r}-1) !}\right]$

where, $N(Q)$ can be obtained by solving this equation with Cardon's method:

$\frac{\theta \lambda[\mathrm{N}(\mathrm{Q})]^{3}}{6}+\lambda \mathrm{N}(\mathrm{Q})-\mathrm{Q}=0$

The given system is convex. Hence the optimal order economic quantity can be obtained by differentiating Eq. 12 with respect to $\mathrm{Q}$ and putting equal to zero:

$$
\begin{aligned}
& {\left[\mathrm{A}_{0} \mathrm{~W}(\mathrm{Q})\right]\left[\frac{\mathrm{K}^{\mathrm{r}}[\mathrm{N}(\mathrm{Q})]^{\mathrm{r}-2} \mathrm{~S}}{(\mathrm{r}-2) !}\right]} \\
& +\left[\mathrm{C}_{0} \mathrm{~W}(\mathrm{Q})\right]\left[\frac{\mathrm{K}^{\mathrm{r}}[\mathrm{N}(\mathrm{Q})]^{\mathrm{r}-2} \mathrm{~S}}{(\mathrm{r}-2) !}\right] \\
& +\mathrm{C}_{0}\left[\frac{\mathrm{K}^{\mathrm{r}}[\mathrm{N}(\mathrm{Q})]^{\mathrm{r}-1} \mathrm{~S}}{(\mathrm{r}-1) !}\right]+\left[\mathrm{iC}_{0} \mathrm{QrW}(\mathrm{Q})\right]\left[\frac{\mathrm{K}^{\mathrm{r}}[\mathrm{N}(\mathrm{Q})]^{\mathrm{r}-1} \mathrm{~S}}{(\mathrm{r}-1) !}\right] \\
& +\left[\mathrm{iC}_{0}\right]\left[\frac{\mathrm{K}^{\mathrm{r}}[\mathrm{N}(\mathrm{Q})]^{\mathrm{r}} \mathrm{S}}{(\mathrm{r}-1) !}\right]=0
\end{aligned}
$$

where, $\mathrm{N}^{\prime}(\mathrm{Q})=\mathrm{W}(\mathrm{Q})$.

This equation can be solved for the optimal $Q$ by using numerical methods such as Newton-Raphson method.

\section{RESULTS AND DISCUSSION}

Numerical illustrations: On solving with the values considered the Table 1-4 have been obtained.

$\mathrm{C}_{0}=\mathrm{Rs} 10, \mathrm{I}=0.01, \mathrm{k}=1.05, \mathrm{~A}_{0}=100$, both the cases with constant as well as stock dependent demand has been considered:

Case I when $\lambda=100$ (constant)

Case II when $\lambda+\alpha+\beta^{\mathrm{r} 1}$, where $\alpha=100, \beta=1.05, \mathrm{r}_{1} 1 / 2$

Observations of the tables and graphs (Fig. 1-4):

- It is seen that with increase in value of $r$ cost of inventory increases

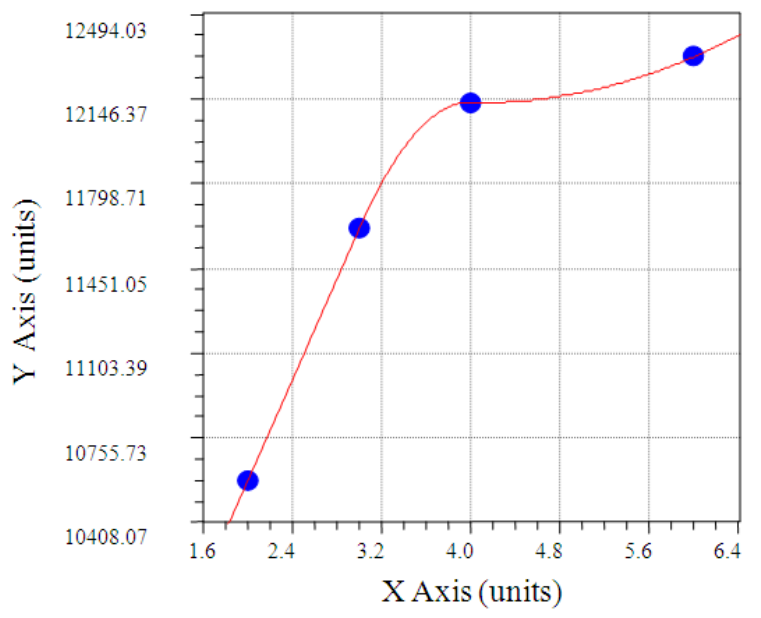

Fig. 1: Graph of Table 1

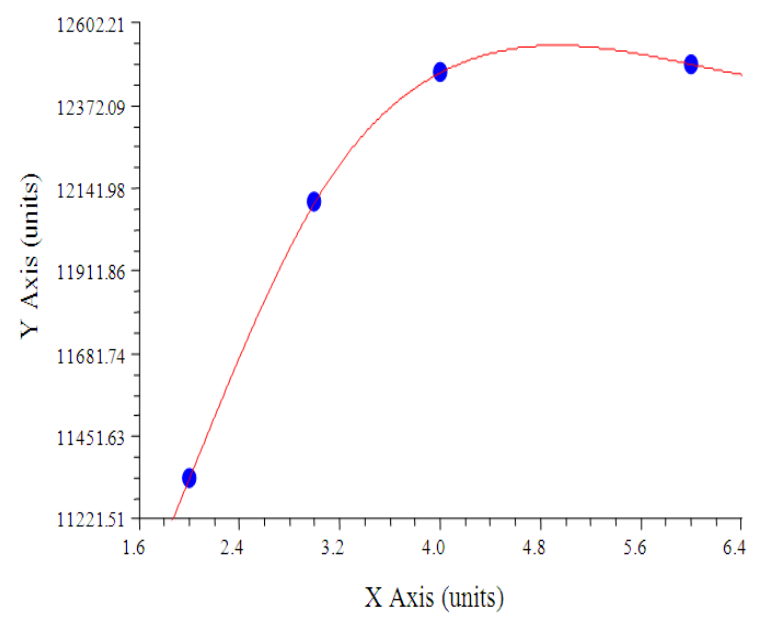

Fig. 2: Graph of Table 2 


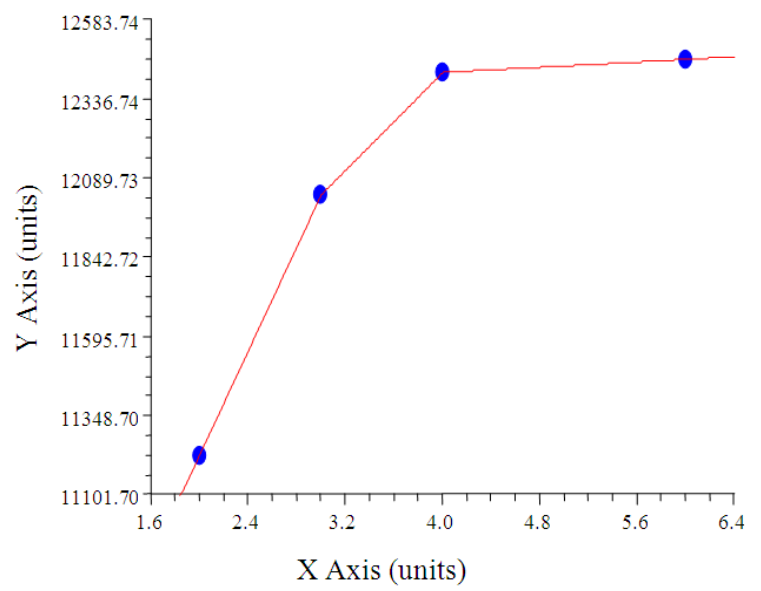

Fig. 3: Graph of Table 3

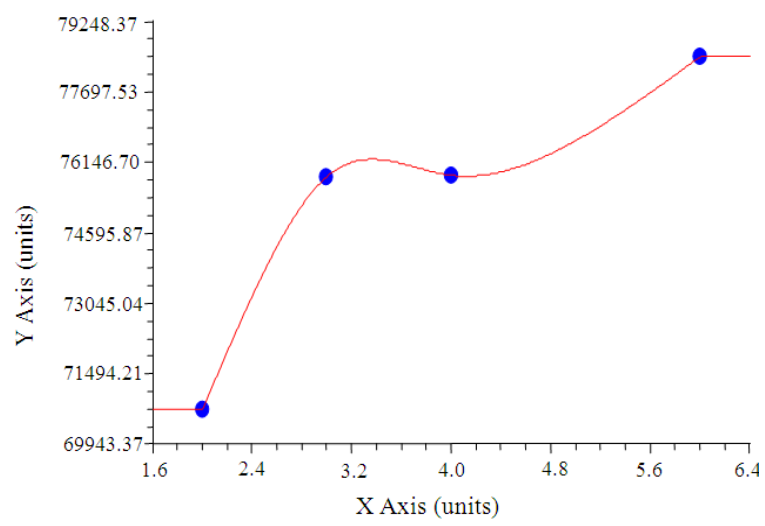

Fig. 4: Graph of Table 4

- It is observed that with the rise in initial inventory the demand for goods also increases hence holding cost also increases

- The optimal inventory cost increases with increase in number of cycles it increase rapidly in starting but becomes stable for large number of cycles

- The cost are convex, hence we can easily find optimal inventory level under the effect of inflation

- This model also provides equation for optimal ordering quantity which can be determined by Newton-Raphson method

\section{CONCLUSION}

In this study, we have presented an optimization framework to derive optimal ordering quantity over a fixed planning horizon for items with a stock-dependent demand rate and under inflationary conditions. This model helps managers to determine the optimal ordering quantity for perishable items such as computer packages, photographic film, radioactive material which exhibit stock dependent demand. New inflation rate has been introduced, which is more suitable for present situation. Numerically it has been proved that inflation has a great role to play in inventory management. Comparative study between the total cost of constant demand and stock dependent demand under the effect of inflation has also been done.

The model taken up in this study can be extended further. For instance, we may extend the model to allow a two parameter, Weibull distribution deterioration rate. Also we can consider variable rate of inflation. Even with this rate of deterioration we can consider the demand as a function of price as well as time varying demand. Furthermore, we could generalize the model to allow for quantity discounts and permissible delay in payments. This model can also renovate into a probabilistic demand pattern with inflation and time value of money. This study will act as catalyst for further research in this direction.

\section{REFERENCES}

Baker, R.C. and T.L. Urban, 1988. A deterministic inventory system with an inventory-leveldependent demand rate. J. Operat. Res. Soc., 39: 823-831. http://www.jstor.org/pss/2583525

Buzacott, E.O.Q., 1975. With inflation for deteriorating items. Operat. Res. Q., 26: 553-558.

Chandra, M.J. and M.L. Bahner, 1985. The effects of inflation and the time-value of money on some inventory systems. Int. J. Prod. Res., 23: 723-730. DOI: $10.1080 / 00207548508904740$

Covert, R.P. and G.C. Philip, 1973. An EOQ model for items with Weilbull distribution deterioration. AITE Trans., 5: 323-329. DOI: 10.1080/05695557308974918

Datta, T.K. and A.K. Pal, 1990. A note on an inventory model with inventory-level-dependent demand rate. J. Operat. Res. Soc., 41: 971-975. http://www.jstor.org/pss/2583275

Frimpong, J.M. and E.F. Oteng-Abayie, 2010. When is inflation harmful? Estimating the threshold effect for Ghana. Am. J. Econ. Bus. Admin., 2: 232-239. DOI: $10.3844 / .2010 .232 .239$

Ghare, P.M. and G.F. Schrader, 1963. A model for exponentially decaying inventories. J. Ind. Eng., 14: $238-243$.

Giri, B.C. and K.S. Chaudhari, 1998. Deterministic models of perishable inventory with stock dependent demand rate and non-linear holding cost. Eur. J. Operat. Res., 105: 467-747. DOI: 10.1016/S0377-2217(97)00086-6 
Goh, M., 1994. EOQ models with general demand and holding cost functions. Eur. J. Operat. Res., 73: 50-54. DOI: 10.1016/0377-2217(94)90141-4

Gupta, R. and P. Vrat, 1986. Inventory model for stock dependent consumption rate. Opsearch, 23: 19-24.

Hou, K.L., 2006. An inventory model for deteriorating items with stock-dependent consumption rate and shortages under inflation and time discounting. Eur. J. Operat. Res., 168: 463-474. DOI: 10.1016/j.ejor.2004.05.011

Levin, R.I., C.P. McLaughlin, R.P. Lamone and J.F. Kottas, 1972. Productions Operations Management: Contemporary Policy for Managing Operating Systems. McGraw-Hill, New York, XI., ISBN: 0070373698, pp: 542.

Mandal, B.N. and S. Phaujdar, 1989. An inventory model for deteriorating items and stock-dependent consumption rate. J. Operat. Res. Soc., 40: 483-488. http://www.jstor.org/stable/2583620

Mandal, M. and M. Maiti, 1999. Inventory of damageable items with variable replenishment rate, stock-dependent demand and some units in hand. Applied Math. Model., 23: 799-807. DOI: 10.1016/S0307-904X(99)00018-9

Mishra, R.B., 1975. A study of inflatioary effects on inventory system. Logist. Spectrum, 9: 260-268.

Mishra, R.B., 1979. A note on optimal inventory management under inflation. Naval Res. Logist. Q., 26: 161-165. DOI: 10.1002/nav.3800260116

Padmanabhan, G. and P. Vrat, 1995. EOQ models for perishable items under stock dependent selling rate. Eur. J. Operat. Res., 86: 281-292. DOI: 10.1016/0377-2217(94)00103-J
Ray, J. and K.S. Chaudhari, 1997. An EOQ model with stock-dependent demand, shortage, inflation and time discounting. Int. J. Prod. Econ., 53: 171-180. DOI: $10.1016 / \mathrm{S} 0925-5273(97) 00112-6$

Sarkar, B.R., A.M.M. Jamal and S. Wang, 2000. Supply Chain models for perishable products under inflation and permissible delay in payments. Comput. Operat. Res., 27: 59-75. DOI: 10.1016/S0305-0548(99)00008-8

Shah, Y.K., 1977. An order level lot size inventory model for deteriorating items. IIE Trans., 9: 108-112. DOI: $10.1080 / 05695557708975129$

Silver, E. and R. Peterson, 1985. Decision Systems for Inventory Management and Production Planning. 2nd Edn., John Wiley and Sons, New York, ISBN: 10: 0471867829, pp: 736.

Su, C.T., L.I. Tong and H.C. Liao, 1996. An inventory model under inflation for stock dependent consumption rate and exponential decay. Opsearch, 33: $72-82$.

http://direct.bl.uk/bld/PlaceOrder.do?UIN=019055 $887 \&$ ETOC $=$ RN\& from $=$ searchengine

Subbaiah, K., K. Rao and B. Satyanarayana, 2004. Inventory models for perishable items having demand rate dependent on stock level. Opsearch, 41: 7-19.

Teng, J.T. and C.T. Chang, 2005. Economic production quantity models for deteriorating items with priceand stock dependent demand. Comput. Operat. Res., 32: 297-308. DOI: 10.1016/S03050548(03)00237-5 